\title{
CULTURA POLÍTICA E PODER LOCAL: ESTATISMO SEGUNDO OS VEREADORES DE SANTA CATARINA 12
}

\author{
Filipe Vicentini Faeti ${ }^{3}$ \\ Éder Rodrigo Gimenes ${ }^{4}$
}

\begin{abstract}
RESUMO
Os estudos sobre elites são pautados na relevância desse conjunto de atores políticos nos processos democráticos, especialmente se baseados no argumento de que se a cultura política dos cidadãos em geral importa, a cultura política daqueles responsáveis pela gestão do Estado é ainda mais relevante. De modo geral, as pesquisas sobre o tema enfocam elites nacionais ou regionais, como deputados federais e estaduais ou burocratas partidários, mas pouca atenção foi conferida até o momento àqueles responsáveis pelo poder local. Nesse sentido, o objetivo deste artigo é analisar a cultura política de vereadores do estado de Santa Catarina, especificamente com relação às suas opiniões e valores quanto ao papel do Estado no que se refere ao desenvolvimento social e econômico brasileiro. Para tanto, utilizamos o banco de dados decorrente do survey que mapeou, de maneira censitária, as câmaras municipais daquela unidade da federação e cujos rendimentos analíticos foram pouco explorados até o momento. De maneira detalhada, a análise recai sobre aspectos como a redução da miséria versus a elevação do número de empregos, o entendimento de que determinadas áreas de políticas públicas devem ser responsabilidade do Estado versus a responsabilidade do mercado e a visão dos vereadores sobre o Programa Bolsa Família, de modo que nossos resultados apontam que a elite legislativa municipal catarinense entende que o combate à pobreza cabe ao Estado, mas não se vê como agente responsável pela redução das desigualdades sociais.
\end{abstract}

Palavras-chave: Elites. Vereadores. Cultura política. Estatismo. Santa Catarina.

\begin{abstract}
The studies on elites are based on the relevance of this set of political actors to democratic processes, especially based on the argument that, if the political culture of citizens in general matters, the political culture of those responsible for state management is even more relevant. In general, researchs on the subject focuses on national or regional elites, such as federal and state deputies or party bureaucrats, but little attention has been paid to those in charge of local power. In this sense, the objective of this article is to analyze the political culture of city councilors of the state of Santa Catarina, specifically regarding their opinions and values regarding the role of the State in relation to Brazilian social and economic development. To do so, we used the database resulting from the survey that mapped, in a census manner, the municipal councils of that unit of the federation and whose analytical yields were little explored so far. In a detailed way, the analysis focuses on aspects such as the reduction of misery versus the increase of jobs, the understanding that certain areas of public policies should be the responsibility of the State or the market and the vision of the councilors on the Bolsa Família Program. Our results point out that the municipal legislative elite in Santa Catarina understands that the fight against poverty rests with the State, but it is not perceived as an agent responsible for reducing social inequalities.
\end{abstract}

Keywords: Elites; Aldermen; Political Culture; Statism; Santa Catarina.

\section{RESUMEN}

Los estudios sobre elites se basan en la relevancia de este conjunto de actores políticos a los procesos democráticos, especialmente en el argumento de que, si la cultura política de los ciudadanos en general importa, la cultura política de los responsables la gestión del Estado es todavía más relevante. En general, las encuestas sobre el tema enfocan a las élites nacionales o regionales, como diputados federales y estatales el burócratas partidarios, pero poca atención se ha conferido hasta el momento a cargo del gobierno local. En este sentido, el

\footnotetext{
${ }^{1}$ Enviado: $31 / 10 / 2017$. Aceito: 10/11/2017.

${ }^{2}$ DOI: http://dx.doi.org/10.5380/recp.v9i1.56153

${ }^{3}$ Graduado e mestrando em Ciências Sociais pela Universidade Estadual de Maringá. Pesquisador do Núcleo de Pesquisas em Participação Política. Contato: fvfaeti@gmail.com

${ }^{4}$ Doutor em Sociologia Política pela Universidade Federal de Santa Catarina. Professor dos Programas de PósGraduação em Ciências Sociais e em Políticas Públicas da Universidade Estadual de Maringá e do Centro Universitário de Maringá. Pesquisador do Núcleo de Pesquisas em Participação Política. Contato: ergimenes@uem.br
} 
objetivo de este artículo es analizar la cultura política de los legisladores municipales del estado de Santa Catarina, específicamente con relación a sus opiniones y valores en lo que se refiere al papel del Estado con relación al desarrollo social y económico brasileño. Para ello utilizamos el banco de datos derivado del survey que mapeó, de manera censitaria, las cámaras municipales de aquella parte de la federación y los ingresos rendimientos analíticos que poco explorados hasta el momento. De modo detallado, el análisis recaí sobre aspectos como la reducción de la miseria versus la elevación de los empleos, el entendimiento de que ciertas áreas de políticas públicas deben ser responsabilidad del Estado o del mercado y la visión de los concejales sobre el Programa Bolsa Familia. Nuestros resultados apuntan que la elite legislativa municipal catarinense entiende que el combate a la pobreza es competencia al Estado, pero no se percibe como agente responsable de la reducción de las desigualdades sociales.

Palabras clave: Elites; Legisladores Municipales; Cultura política; Estatismo; Santa Catarina.

\section{CONSIDERAÇÕES INICIAIS}

Um dos fundadores do elitismo como teoria politológica afirmou que o estudo das minorias politicamente ativas deveria ser a atividade principal dos cientistas políticos (MOSCA, 1896/1992). Considerando que, invariavelmente, todas as sociedades humanas são divididas entre "dirigentes" e "dirigidos", esse autor acreditava que a análise da composição e atuação desse grupo poderia apresentar informações privilegiadas sobre o funcionamento de qualquer sistema político. Pode-se questionar vários dos pressupostos inerentes à abordagem elitista, mas é muito difícil defender a irrelevância desse estrato politicamente ativo para a configuração de qualquer fenômeno político contemporâneo, mesmo em regimes democráticos, onde a participação popular é incentivada.

Mesmo tendo passado por períodos de retração, como nas décadas de 1960 e 1970, graças a fortes críticas de orientação marxista, institucionalista e estruturalista, na atualidade uma profícua agenda elitista dá sinais de muita vitalidade nos cenários internacional e nacional (PERISSINOTTO; CODATO, 2008) $)^{5}$. Reconhecendo-se essa relevância, a presente proposta de pesquisa toma como objeto uma parte dessa elite política nacional que, até o presente momento, tem sido alvo de atenção da literatura nacional apenas de modo marginal: os membros do poder legislativo municipal. Se as elites parlamentares federais (LEAL, 1978; CARVALHO, 1996; LIMA; CHEIBUB, 1996; CODATO, 2008; ALMEIDA; LÜCHMANN; RIBEIRO, 2012), as regionais (PERISSINOTTO et al., 2007) e, até mesmo, as não estatais (GIMENES, 2011) têm sido alvos de análise, permanece pouco estudada a fração da classe política que atua nas Câmaras de Vereadores dos municípios brasileiros. Nesse sentido, nossa preocupação se desloca para os valores dessas elites.

Assim, o objetivo deste artigo é analisar a cultura política de vereadores do estado de

\footnotetext{
${ }^{5}$ No Brasil, essa agenda tem importantes conexões com os estudos sobre carreiras políticas, que buscam produzir diagnósticos sobre as bases de recrutamento das elites políticas no contexto pós-redemocratização (MARENCO; SERNA, 2007; CORADINI, 2007).
} 
FAETI, F. V; GIMENES, E. R. Cultura política e poder local: estatismo segundo os vereadores de Santa Catarina

Santa Catarina, especificamente com relação às suas opiniões e valores no que se refere ao papel do Estado com relação ao desenvolvimento social e econômico brasileiro, o que chamamos, neste artigo, de "estatismo".

Para tanto, além desta seção introdutória, este artigo contempla ainda a discussão sobre elitismo político e estatismo, bem como expõe aspectos metodológicos relacionados ao banco de dados, à apresentação e à análise dos resultados, encerrando-se com considerações que, mais do que concluir o trabalho, apontam possibilidades para expansão da agenda de pesquisas vinculadas à temática.

\section{ELITISMO POLÍTICO E ESTATISMO}

A análise de fenômenos políticos pelo viés cultural é antiga, de modo que autores como Platão, Aristóteles, Maquiavel e Tocqueville já empregavam esse modelo de leitura da realidade em suas respectivas obras. Contudo, a institucionalização desse campo da Ciência Política ocorreu a partir da publicação do livro "The Civic Culture" (ALMOND; VERBA, 1963/1989), no qual a cultura política foi definida como uma configuração de padrões de orientação em relação a objetos políticos partilhados por seus membros, sendo que tais orientações estão no cerne das motivações da atuação dos atores sociais no campo da política.

Considerando-se que o sistema político é classificado como o conjunto de estruturas de encaminhamento e satisfação de demandas, de maneira sintética (ou mesmo simplista), seria possível afirmar que, ao funcionamento do sistema político, é necessária a "construção de uma conexão entre variáveis individuais e estruturas políticas” (GIMENES, 2014, p. 122). Portanto, a legitimidade de um sistema político passaria pela adesão dos indivíduos, no plano abstrato e concreto, a um regime, sendo tal adesão influenciada pela divisão em classes e conforme os padrões culturais, políticos e econômicos que definem hierarquias de importância entre as disposições individuais que delimitam ou não a atuação dos distintos grupos que compõem a coletividade.

Nesse sentido, Dahl (1997) destacou as crenças de ativistas políticos como um dos fatores que favorecem o estabelecimento de regimes democráticos. Em uma frase que sintetiza o conjunto dos seus argumentos sobre o tema, o autor afirma que seria difícil que um regime dessa natureza pudesse vir a existir sem que uma camada politicamente atuante acreditasse nos méritos da democracia e rejeitasse fortemente as demais alternativas de caráter autoritário.

Entendendo que pessoas diferentes provocam efeitos distintos em qualquer sistema 
político, Dahl (1997) propõe como importante questão a identificação de quem alimenta quais crenças políticas. Apesar de ressaltar que essa abordagem não implica na desconsideração dos valores difundidos entre o restante da população, o autor aponta que o conjunto de valores das camadas politicamente mais atuantes e envolvidas com as atividades políticas pode ser um importante fator nos estudos sobre as poliarquias.

Esses ativistas políticos, diferentemente da maioria das pessoas, teriam sistemas de crenças complexos e ricos, o que poderia ser explicado, em grande medida, pela associação entre essa sofisticação e os níveis de escolaridade e interesse por política de tais ativistas. Ademais, no que diz respeito à dimensão estritamente cognitiva da cultura política, o autor é categórico ao afirmar que é plausível supor que o conhecimento sobre os diferentes aspectos da vida política de um país qualquer seja maior entre os membros dessa elite do que entre a população geral (DAHL, 1997).

Com relação às elites, em toda sociedade existe uma minoria que, por diferentes caminhos e/ou maneiras, é detentora do poder, em contraposição a uma maioria que dele se encontra privada. Tal observação remonta à construção do método histórico presente na obra "Elementi di Scienza Politica", no qual o clássico Gaetano Mosca (1896/1992) analisa as regularidades mais significativas presentes nas sociedades ao longo da história e aponta que em diversas civilizações ocorreu um padrão comum de formação de duas classes distintas, classificadas como "dominante" e "massa". Diante de tal constatação, o estudo do arranjo da elite e de suas estratégias de atuação possibilitaria aos cientistas políticos reter informações cruciais quanto a estrutura do sistema político como um todo.

Apesar das várias críticas elaboradas contra os pressupostos da teoria elitista, sendo também considerados clássicos dessa corrente Vilfredo Pareto (1984) e Robert Michels $(1911 / 1992)^{6}$, é inegável que, mesmo no atual regime democrático, existem grupos politicamente ativos que controlam os processos de elaboração e decisão política, ainda que haja, atualmente, maior incentivo à participação popular.

Diante do exposto, corroboramos os argumentos presentes nas obras de autores como Mosca (1896/1992), Pareto (1984), Michels (1911/1982), Dahl (1997), Grynszpan (1996), Lima e Cheibub (1996) e Perissinotto et al. (2007), que afirmam que as elites importam e que desconsiderar que esse grupo exerce influência no processo político seria, no mínimo, ingênuo. Em consequência disso, os valores desta elite importam mais do que os da população em geral, pois, querendo ou não, são os seus membros que estão no comando do processo

\footnotetext{
${ }^{6}$ Para uma revisão sobre as discussões presentes nos textos clássicos da teoria elitista, ver Gimenes (2014).
} 
FAETI, F. V; GIMENES, E. R. Cultura política e poder local: estatismo segundo os vereadores de Santa Catarina

decisório, sendo que as suas decisões afetam um grande leque de pessoas. Assim, se a cultura política deve ser considerada um importante fator explicativo para os fenômenos políticos contemporâneos, os valores, crenças e atitudes daquelas pessoas que estão mais diretamente envolvidas nos processos políticos possuem uma relevância ainda maior (GIMENES, 2014).

Ainda que reconhecer o papel relevante das elites políticas não implique a negação da importância de outros atores sociais, uma vez que o comportamento daquele grupo também se fundamenta nas pressões advindas de outras classes que compõe a coletividade, a percepção das elites sobre os problemas sociais é uma dimensão crucial e fortemente explicativa para a compreensão das relações desiguais no âmbito do Estado e para a identificação de maneiras para se diminuir tais desigualdades (REIS, 2000; SCALON, 2007; GIMENES; RIPARI; RIBEIRO, 2013).

Para trabalhar temáticas como pobreza, desigualdade e estatismo a partir da visão da população brasileira de modo geral, é necessário retornar e destacar o trabalho "Justiça, como igualdade? A percepção da elite e do povo brasileiro" (SCALON, 2007), que apresenta um panorama das percepções de dois grupos distintos acerca de um mesmo objeto, a desigualdade social. A autora argumenta que o Brasil tem como principal traço as desigualdades sociais e aponta que seria frutífero mapear como esse fenômeno surge e se desenvolve em nossa sociedade por fatores políticos, econômicos e sociais, para então, de fato, termos noção a respeito das condições necessárias para a implementação de políticas sociais com o objetivo de gerar equilíbrio de oportunidades entre os indivíduos.

Em sua pesquisa, a autora considerou como "elite" os $10 \%$ da população com maior renda familiar, justificando sua escolha por critério de classe social com base no argumento da "mobilidade social como mecanismo de transmissão e herança, que passa pela origem determinada do indivíduo por sua classe da família a qual ele pertence" (SCALON, 2007, p. 127).

Os resultados nos mostram que ambos os grupos ("elite econômica/social" e "massa") responderam que as diferenças de renda são elevadas no Brasil, o que seria reflexo do discurso de justiça social circulado diariamente pelos meios de comunicação. Porém, em se tratando de remuneração, a elite entendeu que as disparidades salariais deveriam ser maiores do que se apresentam na prática, especialmente com relação às ocupações com diferentes status e prestígio.

Quanto à temática do estatismo, Scalon (2007) aponta que elite e massa tendem a priorizar a questão social em detrimento da individual, o que decorreria do fato de as perguntas do survey não deixarem nítidas as dualidades entre, por exemplo, igualdade social e 
liberdade individual ou a preferência por um Estado de bem-estar social em oposição a um Estado regido pela lógica competitiva do mercado. Ambos os grupos apontam o Estado como quem deveria arcar com a responsabilidade sobre as políticas de distribuição condicionada de renda e aquelas de cunho social.

Esta visão da elite econômica acerca do papel do Estado está em consonância com os achados empíricos de Reis (2000), cujo estudo sobre elites militares, religiosas, intelectuais e econômicas apontou, de modo geral, que a cultura política do grupo é permeada pela percepção de que o Estado é o principal responsável pelo combate às desigualdades, além da noção de que tanto a população em geral quanto as elites não se reconhecem como agentes políticos capazes de combater, ainda que em distintas medidas, o problema da desigualdade —o grupo analisado, inclusive, afirmava desejar a igualdade, mas suas manifestações de ações políticas não buscavam a promoção efetiva da mobilidade social, e sim a garantia de manutenção do status quo.

Segundo a autora, com exceção de poucos estudos sobre estratificação social, na virada do século ainda seria reduzido o número de análises acerca da relação entre as dinâmicas das estruturas desiguais que compõe a sociedade, afirmando que, "[...] mais surpreendente ainda, não existem entre nós estudos sistemáticos sobre como os não-pobres e particularmente as elites percebem a pobreza e a desigualdade" (REIS, 2000, p. 144). Nesse sentido, Reis reforçou o argumento anteriormente exposto de que a compreensão do comportamento e da visão das elites era relevante, uma vez que tal grupo tem papel central na implementação de políticas sociais.

Dentre os resultados de sua pesquisa, cabe destacar, ainda, a conclusão de que as elites brasileiras não se sentem responsáveis pelos problemas da pobreza e da desigualdade e entendem que o cuidado sobre ambos cabe ao Estado, cuja desorganização torna inoperante. Contudo, os indivíduos que compõem as elites políticas e burocráticas (parlamentares do Congresso Nacional e ocupantes de posições privilegiadas nos órgãos públicos, respectivamente) não se veem como "Estado". Assim, a falta de ação política estaria relacionada à omissão da elite, despida de consciência de coletividade, que responsabiliza o Estado pela pobreza, mas retira de si sua parcela dessa responsabilidade, que é coletiva.

Em diálogo com tais resultados, Gimenes, Ripari e Ribeiro (2013) discutiram a percepção das elites políticas não estatais acerca das noções de desigualdade, de pobreza e do papel do Estado. Dentre seus achados, destacamos que o combate à pobreza não se colocava como questão nacional central ao grupo, composto por gestores de entidades sociais e participantes de conselhos municipais de políticas públicas relacionados à área social. Ainda, 
FAETI, F. V; GIMENES, E. R. Cultura política e poder local: estatismo segundo os vereadores de Santa Catarina

atribuíram a questões estruturais do Estado e a seus administradores a responsabilidade pela pobreza. Quanto à sua percepção a respeito de possíveis medidas para minimizar o problema da pobreza, os membros desse grupo apontaram que a melhor forma de combater o pauperismo seria por meio de iniciativas sem fins lucrativos e com finalidade social, enaltecendo, portanto, a atuação de entidades como aquelas das quais são gestores.

Considerando os resultados das análises expostas, os quais, mesmo que não esgotem a discussão, são representativos do debate, constatamos que as questões da pobreza e da desigualdade são parcialmente relevantes às elites brasileiras, mas tal relevância encontra-se relacionada à responsabilização do Estado por tais questões sociais. Nesse sentido, denota-se a importância de se verificar como vereadores, atores da elite política que atuam no âmbito municipal - portanto, mais próximos dos problemas sociais do que parlamentares e agentes do Executivo de ordem estadual ou federal —, entendem que o Estado deve atuar no sentido de reduzir desigualdades e de combater a pobreza, o que acreditamos ser possível a partir da análise de indicadores de estatismo.

\section{ESTATISMO SEGUNDO OS VEREADORES DE SANTA CATARINA}

Os dados analisados neste artigo decorrem da pesquisa "1 ${ }^{\circ}$ Censo do Legislativo Municipal Catarinense”, promovida ao longo da gestão 2013-2016 do poder legislativo local por meio de parceria estabelecida entre a Escola do Legislativo da Assembleia Legislativa de Santa Catarina (ALESC) e a Universidade Federal de Santa Catarina (UFSC). A base de dados é ampla, contempla informações sobre as câmaras municipais, servidores e vereadores e foi, até o momento, pouco explorada, de modo que foram publicados apenas um livro (MICK et al., 2015), um artigo em periódico (AYRES; OLIVEIRA; GIMENES, 2017) e uma coletânea (GIMENES; BORBA, 2018a) a esse respeito.

Em ambas as pesquisas publicadas há informações descritivas sobre o perfil dos vereadores catarinenses, de modo que nos dedicamos, nesta seção, a explorar suas percepções acerca do papel do Estado com relação a questões econômicas e de enfrentamento à pobreza e às desigualdades, bem como à tentativa de identificar preditores de posições mais favoráveis à intervenção do Estado em tais temáticas por parte dos vereadores.

Em se tratando dos indicadores de estatismo, primeiramente verificamos que, diante do questionamento acerca de possibilidades de melhora efetiva das condições de vida do povo, os vereadores foram questionados se o combate à miséria seria mais relevante do que a geração de empregos. Apenas um quarto dos respondentes concordaram com tal afirmação, 
achado que coaduna com os resultados de Reis (2000), Scalon (2007) e Gimenes, Ripari e Ribeiro (2013), no sentido de que redução da pobreza não constitui uma prioridade a ser combatida pelas elites legislativas municipais catarinenses.

TABELA 1 - POLÍTICA DE COMBATE À MISÉRIA VERSUS GERAÇÃO DE EMPREGO

\begin{tabular}{c|c|c}
\hline Afirmação & Concorda & Discorda \\
\hline $\begin{array}{c}\text { Para a melhora do país, o combate à miséria e à fome por meio } \\
\text { de políticas sociais é mais relevante do que gerar empregos }\end{array}$ & $25,1 \%$ & $74,9 \%$ \\
\hline
\end{tabular}

FONTE: Pesquisa $1^{\circ}$ Censo Legislativo Municipal Catarinense.

Quando interrogados a respeito da sua preferência entre a manutenção da taxa de inflação estável com garantia de crescimento, ainda que mínimo, do Brasil ou o impulsionamento do avanço da economia nacional, ainda que baseado, temporariamente, em uma alta taxa de inflação, a maioria dos vereadores declarou preferência pela garantia da estabilidade da nação, dado que corrobora os resultados de Reis (2000), que apontou a maior preocupação das elites com a taxa de inflação do que com o combate às desigualdades sociais.

TABELA 2 - INFLAÇÃO VERSUS CRESCIMENTO

\begin{tabular}{|c|c|c|}
\hline Afirmação & Concorda & Discorda \\
\hline $\begin{array}{c}\text { É preferível manter a inflação baixa e garantir a estabilidade, } \\
\text { mesmo que momentaneamente, com pequeno crescimento, do } \\
\text { que fazer a economia do país crescer mais rapidamente, mesmo } \\
\text { que temporariamente com inflação alta }\end{array}$ & $56,8 \%$ & $43,2 \%$ \\
\hline
\end{tabular}

FONTE: Pesquisa $1^{\circ}$ Censo Legislativo Municipal Catarinense.

Em se tratando de questões de cunho econômico, a posição contrária dos vereadores com relação à privatização da Petrobrás revela uma posição estatista do grupo, o que não se repete quando verificamos seu posicionamento no que tange à desapropriação de propriedades para fins de reforma agrária. Ainda que a segunda questão esteja sujeita a um viés de respostas, por conta do termo "produtiva" em seu enunciado, tal dado é indicativo de que, a exemplo do verificado por Reis (2000), Scalon (2007) e Gimenes, Ripari e Ribeiro (2013), o reconhecimento dos problemas sociais pelas elites não necessariamente implica alterações na ordem social, uma vez que a resposta não aponta a busca pela superação de desigualdades sociais, mas a manutenção do status quo pelo grupo dominante. Por fim, a maioria dos vereadores declarou-se contrária ao financiamento de campanhas eleitorais exclusivamente por fundos públicos, o que pode estar atrelado, em alguma medida, à necessidade de contribuições de natureza privada às suas campanhas, especialmente tendo em vista que o estado de Santa Catarina é majoritariamente composto por pequenos municípios, nos quais as relações e interesses pessoais podem influenciar sobremaneira o desenvolvimento das 
FAETI, F. V; GIMENES, E. R. Cultura política e poder local: estatismo segundo os vereadores de Santa Catarina

campanhas e o desempenho das candidaturas.

TABELA 3 - QUESTÕES ECONÔMICAS

\begin{tabular}{l|r|r}
\hline \multicolumn{1}{c|}{ Proposta } & \multicolumn{1}{c|}{ Favorável } & \multicolumn{1}{c}{ Contrário } \\
\hline Privatização da Petrobrás & $20,6 \%$ & $79,4 \%$ \\
\hline Desapropriação da propriedade produtiva para fins de reforma agrária & $17,5 \%$ & $82,5 \%$ \\
\hline Financiamento público exclusivo das campanhas eleitorais & $36,6 \%$ & $63,4 \%$ \\
\hline
\end{tabular}

FONTE: Pesquisa $1^{\circ}$ Censo Legislativo Municipal Catarinense.

Ainda, os vereadores foram questionados sobre a responsabilidade pelas políticas públicas e de prestação de serviços. Assim como verificado por Reis (2000), Scalon (2007) e Gimenes, Ripari e Ribeiro (2013), os legisladores municipais catarinenses entendem que o Estado deve ser responsável por educação, saúde, aposentadoria e previdência social, transporte, fornecimento de água e esgoto e recolhimento do lixo. Contudo, ainda que tais direitos sociais sejam garantidos no texto constitucional como deveres do Estado, o entendimento dos vereadores é o de que a intervenção deve ser majoritária por parte do poder público, mas não exclusiva, uma vez que, à exceção da aposentadoria e da previdência social, para todas as áreas/atividades verificamos maior concentração de respostas na categoria "mais governo do que empresas", o que considera a responsabilização também do setor privado com relação às referidas políticas públicas.

TABELA 4 - GRAU DE INTERVENÇÃO DO GOVERNO EM POLÍTICAS PÚBLICAS

\begin{tabular}{l|c|c|c|c}
\hline \multicolumn{1}{c|}{ Área/atividade } & Só governo & $\begin{array}{c}\text { Mais governo do } \\
\text { que empresas }\end{array}$ & $\begin{array}{c}\text { Mais empresas do } \\
\text { que governo }\end{array}$ & Só empresas \\
\hline Educação & $44,0 \%$ & $49,1 \%$ & $5,8 \%$ & $1,1 \%$ \\
\hline Saúde & $44,2 \%$ & $47,7 \%$ & $6,7 \%$ & $1,4 \%$ \\
\hline Aposentadoria e previdência social & $48,7 \%$ & $40,5 \%$ & $8,4 \%$ & $2,3 \%$ \\
\hline Transporte & $21,0 \%$ & $41,7 \%$ & $28,7 \%$ & $8,6 \%$ \\
\hline Fornecimento de água e esgoto & $37,4 \%$ & $41,1 \%$ & $15,7 \%$ & $5,6 \%$ \\
\hline Recolhimento do lixo & $30,8 \%$ & $37,9 \%$ & $21,4 \%$ & $9,9 \%$ \\
\hline
\end{tabular}

FONTE: Pesquisa $1^{\circ}$ Censo Legislativo Municipal Catarinense.

Por fim, nosso último indicador de estatismo diz respeito à opinião dos vereadores com relação ao investimento do Governo Federal em programas sociais, como o Bolsa Família. Com distribuição semelhante entre as percepções dos questionados, verificamos ligeira maioria entre aqueles que entendem que os recursos utilizados em programas de distribuição condicionada de renda deveriam ser investidos em obras de infraestrutura, as quais poderiam alavancar economicamente o país e produzir empregos, em oposição àqueles que reconhecem os investimentos em programas sociais como relevantes para a economia interna do país e a promoção de qualidade de vida da população mais humilde, sentido 
denotado por diversas pesquisas realizadas com beneficiários do Bolsa Família, como a de Rego e Pinzani (2013).

TABELA 5 - GASTOS EM INFRAESTRUTURA VERSUS POLÍTICAS SOCIAIS

\begin{tabular}{l|c}
\hline $\begin{array}{l}\text { Tais investimentos são necessários para o benefício da população mais humilde e } \\
\text { para promover a economia interna do país }\end{array}$ & $48,0 \%$ \\
\hline $\begin{array}{l}\text { Estes recursos deveriam ser aplicados em infraestrutura (hidrelétricas, portos, } \\
\text { rodovias e ferrovias), ajudando o país a alavancar a economia e produzir empregos }\end{array}$ & $52,0 \%$ \\
\hline
\end{tabular}

FONTE: Pesquisa $1^{\circ}$ Censo Legislativo Municipal Catarinense.

Com vistas a refinar a análise no sentido de identificar possíveis preditores do estatismo entre os vereadores do estado de Santa Catarina, construímos um índice a partir do cômputo dos doze indicadores apresentados nas tabelas de 1 a 5, o que foi possível diante do cumprimento do critério necessário à redução dos dados a uma única medida. Este índice contemplou treze pontos, com medidas de 0 a 12 , as quais indicam o quanto os respondentes entendem que o Estado deve desempenhar funções e ser responsável pelo combate à pobreza e pela redução de desigualdades ${ }^{7}$.

TABELA 6 - ÍNDICE DE ESTATISMO

\begin{tabular}{c|c|c}
\hline & $\%$ & $\%$ acum. \\
\hline 1,00 & 0,3 & 0,3 \\
\hline 2,00 & 0,7 & 1,0 \\
\hline 3,00 & 1,5 & 2,5 \\
\hline 4,00 & 2,9 & 5,4 \\
\hline 5,00 & 2,5 & 7,8 \\
\hline 6,00 & 7,3 & 15,1 \\
\hline 7,00 & 13,5 & 28,6 \\
\hline 8,00 & 18,4 & 47,0 \\
\hline 9,00 & 23,5 & 70,5 \\
\hline 10,00 & 18,3 & 88,8 \\
\hline 11,00 & 8,3 & 97,1 \\
\hline 12,00 & 2,9 & 100,0 \\
\hline
\end{tabular}

FONTE: Pesquisa $1^{\circ}$ Censo Legislativo Municipal Catarinense.

Os dados da tabela acima demonstram a maior concentração dos vereadores dentre aqueles que consideram o estatismo como forma de ação do poder público. Verificamos que nenhum respondente assumiu apenas posições contrárias àquelas de defesa do papel do Estado como responsável por ações de políticas de combate à pobreza e de busca pela redução de desigualdades e até o ponto médio da escala (6) encontramos apenas 15,1\% dos

\footnotetext{
${ }^{7}$ Consideramos "estatistas" os vereadores concordantes com as afirmações expostas nas tabelas 1 e 2, os contrários às questões de cunho econômico dispostas na Tabela 3, aqueles que entendem que a responsabilidade por ações e atividades sociais são de responsabilidade majoritária ou exclusiva do Estado (binarizadas as variáveis constantes na Tabela 4) e os que têm a percepção de que o investimento em políticas sociais é mais relevante do que o aporte financeiro em obras de infraestrutura (Tabela 5). O Alpha de Cronbach de ,515 atende ao critério estatístico para redução de dados (WOOLDRIDGE, 2005), o que possibilitou a redução das variáveis destacadas a uma escala integrada (BOHRNSTEDT; KNOKE, 1988).
} 
FAETI, F. V; GIMENES, E. R. Cultura política e poder local: estatismo segundo os vereadores de Santa Catarina

legisladores municipais. A média de estatismo foi de $8,3585^{8}$, o que reforça a afirmação de que os vereadores catarinenses aderem ao estatismo, de modo geral.

A fim de identificar características relacionadas ao estatismo, construímos modelos de regressão linear, tomando como variáveis independentes aspectos sociais e atitudinais que acreditamos poderem contribuir para a diferenciação dos respondentes, sendo eles: sexo, faixa etária, status étnico, escolaridade, autoposicionamento ideológico, capital social e experiência como vereador. Para alguns desses aspectos, a expectativa era de indiferenciação, por conta do entendimento de que, em se tratando de uma elite política específica, haveria relativa homogeneidade de respostas a despeito do sexo e da faixa etária dos vereadores. Por outro lado, esperávamos, amparados pela literatura de comportamento político, que aqueles com status de minoria étnica e os mais escolarizados fossem mais propensos a posições estatistas, assim como indivíduos localizados mais à esquerda no espectro ideológico e os que dispõem de mais vínculos associativos, constitutivos de seu capital social. Por fim, incluímos a variável que diferencia aqueles em primeiro mandato dos vereadores que já ocupavam tal posto a pelo menos um mandato completo, sem expectativa determinada, mas com o intuito de encontrarmos efeitos distintivos.

O modelo linear completo não se revelou significativo de modo geral, assim como nenhum dos preditores apresentou efeito explicativo ao estatismo. Em virtude de tal resultado, inidicativo de que o conjunto de variáveis não explicaria as posições dos vereadores com relação ao papel do Estado diante de questões relacionadas à pobreza e à redução de desigualdades sociais, testamos um segundo modelo, no qual as variáveis são trabalhadas por meio de combinações, a fim de verificar qual conjunto de indicadores tem maior capacidade explicativa para a variável dependente em análise. Tal procedimento retornou um modelo com apenas uma variável, a escolaridade, cujo efeito negativo (-,110, com significância de ,002) nos permitiu inferir que, conforme se eleva o nível de escolarização dos vereadores, reduz-se seu entendimento acerca do desenvolvimento do estatismo por parte do poder público.

Nesse sentido, nosso resultado demonstra que aqueles que ocupam posição de centralidade com relação a recursos cognitivos tendem em menor medida a apoiar ações destinadas à alteração da condição subalterna da parcela com menor acesso às políticas públicas. Ademais, tal resultado denota a hipótese de menor comprometimento político desses vereadores com a redução da pobreza e com o combate às desigualdades, de forma que não colaborariam para a democratização do acesso dos indivíduos aos direitos sociais mínimos

\footnotetext{
${ }^{8}$ Desvio padrão de 1,98265 .
} 
previstos no texto constitucional, o que merece destaque devido ao expressivo conjunto de 43,7\% dos vereadores com alta escolarização e de 33,7\% com escolaridade média. Isso significa que $77,4 \%$ dos legisladores têm menores chances (com intensidades distintas) de manifestar opções favoráveis ao estatismo, diante de 22,6\% com até o Ensino Fundamental completo.

\section{CONSIDERAÇÕES FINAIS}

As elites importam. Nesses termos, é importante destacar que, além dos fatores que tornam as crenças desse grupo particularmente relevantes, tais ativistas desempenham também um papel fundamental nos processos de criação e difusão dos elementos que compõem a cultura política de uma sociedade, sendo, afinal, tais indivíduos que operam as instituições e atuam de maneira mais influente no processo de consolidação das democracias modernas.

Nesse sentido, este artigo trata-se de uma pesquisa inédita, uma vez que aborda resultados do primeiro censo com legislativos municipais realizado para toda uma unidade da federação brasileira, oferecendo informações relevantes para a compreensão não apenas da realidade política estadual, mas também dos desafios que nossas instituições atualmente atravessam para se fortalecerem em termos de legitimidade e apoio popular, principalmente com relação ao estatismo.

Diante de tal contexto, destacamos um conjunto de variáveis pertinentes à temática, cuja análise descritiva trouxe como resultado apontamentos referentes à cultura política dos vereadores catarinenses no que tange às suas percepções quanto ao estatismo. Em diálogo com resultados de pesquisas anteriores, nossos resultados apontam que a pobreza não constitui uma prioridade a ser combatida pelas elites legislativas municipais de Santa Catarina, de modo que, dentre suas preocupações relacionadas a aspectos econômicos e sociais, destacam-se o combate à inflação e os investimentos em políticas públicas de saúde e educação.

Para esse conjunto de indivíduos, a melhoria nas condições de vida dos brasileiros depende do aperfeiçoamento da administração do Estado. No entanto, apesar de reconhecerem a responsabilidade do poder público com relação à redução da pobreza e ao enfrentamento das desigualdades sociais, o que nos permite considerá-los estatistas, a prioridade desta elite não é o combate às disparidades, mas a manutenção do status quo.

Dado que nos últimos anos o Brasil tem sido palco de ondas de protestos nas quais é 
FAETI, F. V; GIMENES, E. R. Cultura política e poder local: estatismo segundo os vereadores de Santa Catarina

recorrente o descontentamento dos eleitores com a política e com os políticos, bem como as discussões sobre o caráter representativo da democracia nacional, a pesquisa justifica-se também pela possibilidade de análise dos valores dos legisladores municipais catarinenses com relação ao estatismo. Nesses termos, a menor preocupação dos vereadores com mais escolarização em atuar no sentido de promover a intervenção social do Estado reforça o sentido elitista de sua cultura política.

\section{REFERÊNCIAS}

ALMEIDA, C. C. R.; LÜCHMANN, L. H. H.; RIBEIRO, E. A. Associativismo e representação política feminina no Brasil. Revista Brasileira de Ciência Política, n. 8, p. 237263, mai./ago. 2012.

ALMOND, G. A.; VERBA, S. The Civic Culture: Political Attitudes and Democracy in Five Nations. 3. ed. New York: Sage, 1989. (Trabalho original publicado em 1963).

AYRES, C. S. L. da S. A.; OLIVEIRA, R. A. de; GIMENES, É. R. O Legislativo municipal catarinense sob a perspectiva de gênero: origem, trajetória e adesão democrática. Revista ELegis, Brasília, n. 22, p. 25-43, jan./abr. 2017.

BOHRNSTEDT, G. W.; KNOKE, D. Statistics for Social Data Analysis. 2. ed. Itasca: Peacock, 1988.

CARVALHO, J. M. A construção da ordem. Rio de Janeiro: Relume-Dumará, 1996.

CODATO, A. A formação do campo político profissional no Brasil: uma hipótese a partir do caso de São Paulo. Revista de Sociologia Política, Curitiba, v. 30, p. 89-105, 2008.

CORADINI, O. L. Engajamento associativo-sindical e recrutamento de elites políticas: tendências recentes no Brasil. Revista de Sociologia e Política, v. 28, p. 181-203, 2007.

DAHL, R. A. Poliarquia: participação e oposição. São Paulo: EDUSP, 1997.

GIMENES, É. R. Cultura política e democracia: apoio difuso e específico entre um segmento da elite não estatal do município de Maringá (PR). 178 f. Dissertação (Mestrado em Ciências Sociais) - Programa de Pós-Graduação em Ciências Sociais, Centro de Ciências Humanas, Letras e Artes, Universidade Estadual de Maringá, Maringá, 2011.

Teoria das elites e as elites do poder: considerações sobre a relevância dos teóricos clássicos e de Wright Mills aos estudos de cultura política e democracia. Revista Agenda Política, v. 2, p. 119-151, 2014.

GIMENES, É. R.; BORBA, J. (Orgs.). Poder legislativo e cultura política: valores, atitudes, trajetória e comportamento político dos vereadores e vereadoras do Estado de Santa Catarina. Curitiba: Comunicação Política e Opinião Pública, 2018. 
GIMENES, É. R.; RIPARI, A.; RIBEIRO, E. A. Desigualdade, pobreza e ações do Estado: a visão de elites políticas não-estatais. Revista Mediações, Londrina, v. 18, n. 1, p. 292-317, jan./jun. 2013.

GRYNSZPAN, M. A teoria das elites e sua genealogia consagrada. Revista Brasileira de Informação Bibliográfica em Ciências Sociais, n. 41, p. 35-83, jan./jun. 1996.

LEAL, V. N. Coronelismo, enxada e voto. 4. ed. Rio de Janeiro: Alfa-Omega, 1978.

LIMA, M. R. S. de; CHEIBUB, Z. B. Instituições e valores: as dimensões da democracia na visão da elite brasileira. Revista Brasileira de Ciências Sociais, São Paulo, n. 31, p. 83-110, 1996.

MARENCO, A.; SERNA, M. Por que carreiras políticas na esquerda e na direita não são iguais? Recrutamento político em Brasil, Chile e Uruguai. Revista Brasileira de Ciências Sociais, v. 22, n. 64, p. 93-113, 2007.

MICHELS, R. Sociologia dos partidos políticos. Tradução de: CHAUDON, A. Brasília: Universidade de Brasília, 1982. (Trabalho original publicado em 1911).

MICK, J. et al. Por dentro das Câmaras: o perfil de vereadores, servidores e do Legislativo Municipal de Santa Catarina. Florianópolis: Assembleia Legislativa do Estado de Santa Catarina, 2015.

.; GIMENES, É. R. Pesquisa $1^{\circ}$ Censo Legislativo Municipal Catarinense. Banco de dados, 2014.

MOSCA, G. La classe politica. México: Fondo de Cultura Econômica, 1992. (Trabalho original publicado em 1896).

PARETO, V. Tratado de Sociologia Geral. In: RODRIGUES, J. A. (Org.). Vilfredo Pareto: Sociologia. São Paulo: Ática, 1984.

PERISSINOTTO, R. et al. (Org.). Quem governa? Um estudo das elites políticas do Paraná. Curitiba: Editora UFPR, 2007.

PERISSINOTTO, R. M.; CODATO, A. Por um retorno à Sociologia das elites. Revista de Sociologia e Política, n. 16, v. 30, p. 7-15, jun. 2008.

REGO, W. L.; PINZANI, A. Vozes do Bolsa Família: autonomia, dinheiro e cidadania. São Paulo: Universidade Estadual Paulista Júlio de Mesquita Filho, 2013.

REIS, E. Percepção da elite sobre pobreza e desigualdade. Revista Brasileira de Ciências Sociais, São Paulo, v. 15, n. 42, p. 143-152, fev. 2000.

SCALON, C. Justiça como igualdade? A percepção da elite e do povo brasileiro. Revista Sociologias, Porto Alegre, v. 9, n. 18, p. 126-149, jun./dez. 2007.

WOOLDRIDGE, J. M. Introdução à econometria: uma abordagem moderna. São Paulo: 
FAETI, F. V; GIMENES, E. R. Cultura política e poder local: estatismo segundo os vereadores de Santa Catarina

Pioneira, 2005. 